\title{
Hospital-based herpes zoster diagnoses in Denmark: rate, patient characteristics, and all-cause mortality
}

Sigrun A. J. Schmidt ${ }^{1 *}$, Johnny Kahlert ${ }^{1}$, Mogens Vestergaard ${ }^{2}$, Henrik C. Schønheyder ${ }^{3,4}$ and Henrik T. Sørensen ${ }^{1}$

\begin{abstract}
Background: Herpes zoster $(\mathrm{HZ})$ may result in severe complications requiring hospital treatment, particularly in patients with comorbidity. Nevertheless, data on $\mathrm{HZ}$ from nationwide population-based hospital registries are sparse.
\end{abstract}

Methods: We conducted a cohort study describing first-time hospital-based (inpatient, outpatient, and emergency room) HZ diagnoses in the Danish National Patient Registry, 1994-2012. We computed the diagnosis rate; prevalence of demographic characteristics, comorbidities, and complications; length of hospital stay; and standardized mortality ratios (SMRs) using the Danish population as reference. We classified comorbidity using the Charlson Comorbidity Index (CCl) scoring system and categorized patients in groups of no (score 0), moderate (score 1), severe (score 2), and very severe comorbidity (score $\geq 3$ ). In addition, we computed the prevalence of certain conditions associated with immune dysregulation (stem cell or bone marrow transplantation, solid organ transplantation, HIV infection, primary immunodeficiency, any cancer, and autoimmune diseases).

Results: The diagnosis rate increased almost exponentially from 6 to 91.9 per 100,000 person-years between age 50 and $\geq 90$ years. The age-standardized rate was stable throughout the study period. The median length of hospital stay was 4 days (interquartile range: 1-8 days) for inpatients with $\mathrm{HZ}$ as the main reason for admission. According to the CCl, $44.3 \%$ of patients had no comorbidity, $17.3 \%$ moderate comorbidity, $17.4 \%$ severe comorbidity, and $21.0 \%$ very severe comorbidity. Comorbidities involving immune dysregulation, such as malignant $(21 \%)$ and autoimmune diseases $(17 \%)$, were particularly prevalent. Thirty percent had neurological, ophthalmic, or other complications. HZ was associated with increased all-cause mortality overall (SMR 1.8, 95 \% Cl: 1.7-1.8), but not in analyses restricted to patients without comorbidity (SMR 1.0, 95 \% Cl: 0.9-1.0).

Conclusions: This study provides estimates of the epidemiology of hospital-based (severe) $\mathrm{HZ}$. The diagnosis rate increased substantially with age. Complications and comorbidities were prevalent, likely resulting in increased mortality.

Keywords: Complications, Epidemiology, Herpes zoster, Hospitalization, Outpatient clinics, Hospital

\section{Background}

Herpes zoster (HZ) is a neurocutaneous infection caused by reactivation of the varicella-zoster virus (human herpesvirus 3 ) from the sensory ganglia when cell-mediated immunity wanes below a critical level [1]. In a review of data from nine European countries, the overall incidence rate in the general population was approximately 100-

\footnotetext{
*Correspondence: saj@clin.au.dk

'Department of Clinical Epidemiology, Aarhus University Hospital, Olof

Palmes Allé 43-45, DK-8200 Aarhus N, Denmark

Full list of author information is available at the end of the article
}

400 per 100,000 person-years in adults aged 50 years or younger. Thereafter, it increased notably, reaching 1000 per 100,000 person-years after age 80 years [2]. The risk of $\mathrm{HZ}$ is increased in patients with cell-mediated immunodeficiency, including that caused by drugs (e.g., corticosteroids or chemotherapy), radiotherapy, viral infections (i.e., human immunodeficiency virus [HIV]), or malignancy.

HZ may have severe acute complications, such as meningo-encephalitis and cutaneous dissemination, in particular among individuals with the aforementioned 
predisposing conditions $[3,4]$. These patients are more likely to be treated in the hospital or in hospital outpatient specialty clinics. When assessing the epidemiology of $\mathrm{HZ}$, it is important also to consider these severe or potentially severe cases diagnosed in a hospital-based setting. Nevertheless, results from nationwide population-based hospital registries in Europe are sparse concerning the diagnosis rate and patient characteristics, including prevalence of complications and comorbidities. In particular, none of the previous population-based studies published data pertaining specifically to diagnoses from hospital outpatient specialty clinics. To address this paucity of data, we conducted a nationwide Danish cohort study describing $\mathrm{HZ}$ in a hospital-based setting, including diagnosis rate, patient demographics, severity, comorbidity burden, length of admission, and subsequent all-cause mortality.

\section{Methods}

The Danish National Health Service provides tax-funded universal health care to all residents (population 5.6 million), guaranteeing unfettered access to general practitioners and hospitals [5]. Utilization of health services is recorded in nationwide databases using the unique central personal register (CPR) number assigned to each Danish resident at birth or immigration [5]. The CPR number allowed for unambiguous individual-level linkage of the registries used in the current study.

The Danish National Patient Registry (DNPR) contains data on all admissions to Danish non-psychiatric departments since 1977 and visits to hospital-based outpatient clinics (i.e., ambulatory medical care) and emergency rooms since 1994 [6]. Each DNPR record contains the CPR number of the patient, dates of hospital admission and discharge or start and end of outpatient contact, information on procedures performed, and diagnoses. Each record includes a primary diagnosis, i.e., the condition considered the main reason for the hospital contact. Diagnoses are assigned by the discharging physician at the time of hospital discharge or at the end of an outpatient contact using the International Classification of Diseases, 8th revision (ICD-8) until the end of 1993 and 10th revision (ICD-10) thereafter [6]. Surgical procedures are coded by the surgeon according to a Danish classification system (1977 through 1995) and a Danish version of the Nordic Medico-Statistical Committee Classification of Surgical Procedures (from 1996 onwards). Since 2002, the DNPR has provided the basis for reimbursing both public and private hospitals. Reporting of all services provided in the private hospital sector became mandatory in 2003. General practitioners and private practice specialists do not report to the DNPR. Diagnosis codes and definitions used are provided in Additional file 1: Table S1.
We used the DNPR to identify all first-time inpatient, outpatient, and emergency room diagnoses of HZ. To ensure complete information on outpatient and emergency room diagnoses and to avoid potential problems associated with the transition between the ICD-8 and ICD-10 coding systems, we chose a study period from January 1, 1994 to December 31, 2012, when ICD-codes were used, exclusively. The date of discharge or end of outpatient contact was considered the diagnosis date. Based on patients' first-ever $\mathrm{HZ}$ diagnosis recorded in the DNPR, we classified HZ diagnoses according to type of hospital-based contact (inpatient, outpatient clinic, or emergency room) and type of diagnosis (primary or secondary). We also identified individual ICD-10 codes for HZ. However, because of the clinical difficulty of distinguishing between $\mathrm{HZ}$ encephalitis and meningitis, we combined ICD-10 codes B02.0 and B02.1 in our analysis. Similarly, we grouped ICD-10 codes according to severity (complicated or uncomplicated) and extent (disseminated or localized), as shown in Additional file 1: Table S1. The difference between groups of complicated and disseminated HZ is attributed to codes for HZ ophthalmicus, which is regarded as a localized but complicated form.

To give an overview of reasons for healthcare contacts among patients with a secondary $\mathrm{HZ}$ diagnosis, we categorized the primary diagnosis according to a list of 203 morbidity groups based on the ICD-8 and ICD-10 World Health Organization morbidity tables. This code list has been published previously [7] and is outlined in detail in Additional file 1: Table S1. Additional codes outside this list comprised general and unspecific reasons for hospital contact. We grouped them into four categories ('Symptoms, signs and abnormal clinical and laboratory findings not otherwise specified', 'Injury, poisoning and certain other consequences of external causes,' 'Observation for or follow-up after treatment for cancer', and 'Contact with health services due to solid organ or bone marrow transplantation, and 'Other factors influencing health status and contact with health services'). The HZ vaccine, which is approved by the European Medicines Agency for use in adults aged 50 years or older, did not become available in Denmark until September 2014, and hence not considered in the present study [8].

To quantify comorbidity, we obtained information on all primary, secondary, and additional diagnoses recorded in the DNPR before or on the same date as the $\mathrm{HZ}$ diagnosis. We classified comorbidity using the Charlson Comorbidity Index (CCI), a scoring system that assigns between one and six points to 19 groups of chronic diseases (Additional file 1: Table S1) according to their ability to predict death [9]. We obtained information on diagnoses in each disease group. Based on the total CCI score, we also categorized patients into levels 
of none (score 0 ), moderate (score 1 ), severe (score 2), and very severe (score 3 or more) comorbidity. We also obtained information on diagnosis history of conditions associated with immune dysregulation (i.e., stem cell or bone marrow transplantation, solid organ transplantation, HIV infection, primary immunodeficiency, any cancer, and autoimmune diseases) and thus potentially an increased $\mathrm{HZ}$ risk [1]. For the categories HIV infection, any cancer, and autoimmune diseases, there was an overlap with codes included in the CCI.

The Danish Civil Registration System (CRS) provides a record of changes in vital and migration status for the entire population since 1968 [5]. We used the CRS to follow $\mathrm{HZ}$ patients from diagnosis until the date of death, emigration, or December 31, 2012.

\section{Statistical analysis}

We computed the annual rate of hospital-based $\mathrm{HZ}$ diagnoses throughout the study period, with direct age standardization [10] to the 2000 Danish census. We characterized patients according to age, sex, comorbidities, calendar period of diagnosis (1994-1999, 20002005, and 2006-2012), and types of HZ diagnoses. For patients with an inpatient primary $\mathrm{HZ}$ diagnosis, we computed the median and total length of hospital stay.

We used the Kaplan-Meier estimator to compute absolute mortality risks. We computed standardized mortality ratios (SMRs) with $95 \%$ confidence intervals (CIs) for $\mathrm{HZ}$ patients using indirect standardization [10], with the general Danish population as reference. The expected number of deaths was obtained by multiplying the number of person-years at risk in the $\mathrm{HZ}$ cohort with the rate of death in the general population according to 5-year age groups, sex, and calendar year. The SMR was computed as the ratio of the observed to the expected number of deaths. Corresponding $95 \%$ CIs were computed assuming that the observed number of deaths followed a Poisson distribution. We performed analyses overall and in subgroups of demographic and patient characteristics.

Analyses were performed using STATA $^{\oplus}$ (version 12.1, STATA, College Station, TX). The study was approved by the Danish Data Protection Agency (record number 1-16-02-1-08). Danish legislation does not require ethical review board approval or informed consent from subjects in registry-based studies.

\section{Results}

\section{Hospital diagnosis rate}

We identified 13,663 first-time hospital-based diagnoses of HZ in Denmark between 1994 and 2012, corresponding to a standardized HZ rate of 13.1 (95 \% CI: 12.9-13.3) per 100,000 person-years (Table 1). The rate was stable throughout the study period, both overall (Fig. 1) and in subgroups defined by age and sex (Additional file 1: Figures S1 and S2).

The $\mathrm{HZ}$ rate varied markedly with age. The rate was 3-6 per 100,000 person-years for persons aged below 50 years after which it increased approximately twofold with each decade of age, reaching 91.1 per 100,000 person-years for those aged 90 years or older (Table 1). For all individuals aged 50 years or more (i.e., those potentially eligible for the $\mathrm{HZ}$ vaccine), the overall diagnosis rate was 30.1 per 100,000 person-years. The increase in rate with age was observed for all subtypes of $\mathrm{HZ}$ diagnoses, but was most pronounced for inpatient diagnoses (Fig. 2).

The standardized diagnosis rate was slightly higher among women than men (13.6 vs. 12.5 per 100,000 person-years). This difference was primarily driven by a difference in rates for persons aged 50-89 years (Table 1).

\section{Type of diagnosis, complications, and length of stay}

Sixty percent of patients were diagnosed with $\mathrm{HZ}$ during a hospital admission, $25 \%$ in an outpatient clinic, and $15 \%$ in the emergency room (Table 2). The majority of diagnoses were primary (72 \%). Reasons for hospital contact among patients with secondary $\mathrm{HZ}$ diagnoses are listed in Additional file 1: Table S2; the most frequent were the unspecific codes 'other factors influencing health status and contact with health services' (8.1 \%) and 'symptoms, signs, and abnormal clinical and laboratory findings' (8.0\%), followed by 'pneumonia' (5.9\%), and 'bronchitis, emphysema and other obstructive pulmonary diseases' (4.8\%). In total, cancer was the primary diagnosis in $9.5 \%$ of patients with a secondary $\mathrm{HZ}$ diagnosis.

Complicated $\mathrm{HZ}$ occurred among $30 \%$ of patients, the most frequent being $\mathrm{HZ}$ ophthalmicus followed by nervous system involvement (Table 2). There was a slight increase in the incidence and proportion of patients with 'HZ encephalitis', 'HZ meningitis' and ' $\mathrm{HZ}$ with other complication' during the study period. Almost half of the outpatient HZ diagnoses were complicated (28\% were HZ ophthalmicus), compared with one-fourth of inpatient and emergency room diagnoses (Additional file 1: Table S3).

The median length of stay for inpatients with a primary $\mathrm{HZ}$ diagnosis was 4 days (interquartile range 1-8 days, mean 6.2 days), increasing with age (Table 1). On average, patients with primary inpatient $\mathrm{HZ}$ diagnoses had an annual total of 1634 inpatient days, of which $88 \%$ were in patients aged 50 years or more. The longest stays were observed in patients with complicated $\mathrm{HZ}$, especially $\mathrm{HZ}$ encephalitis (median 10 days, interquartile range 6-18 days, mean 15.5 days). 
Table 1 Diagnosis rates and median length of stay for hospital-based diagnoses of HZ, Denmark, 1994-2012

\begin{tabular}{|c|c|c|c|c|c|c|c|c|c|c|}
\hline \multirow[t]{2}{*}{ Age (years) } & \multicolumn{3}{|l|}{ Overall } & \multicolumn{3}{|l|}{ Women } & \multicolumn{3}{|l|}{ Men } & \multirow{2}{*}{$\begin{array}{l}\text { Median length } \\
\text { of stay } \\
\text { (interquartile } \\
\text { range), days }\end{array}$} \\
\hline & Number & $\begin{array}{l}\text { Person- } \\
\text { time }\end{array}$ & Rate $^{a}$ & Number & $\begin{array}{l}\text { Person- } \\
\text { time }\end{array}$ & Rate $^{a}$ & Number & $\begin{array}{l}\text { Person- } \\
\text { time }\end{array}$ & Rate $^{a}$ & \\
\hline $0-9$ & 492 & $12,580,957$ & 3.9 & 234 & $6,132,651$ & 3.8 & 258 & $6,448,306$ & 4.0 & $1(0-3)$ \\
\hline 10-19 & 368 & $12,030,773$ & 3.1 & 195 & $5,867,909$ & 3.3 & 173 & $6,162,864$ & 2.8 & $3(1-6)$ \\
\hline $20-29$ & 623 & $13,126,461$ & 4.7 & 303 & $6,473,069$ & 4.7 & 320 & $6,653,392$ & 4.8 & $3(1-6)$ \\
\hline 30-39 & 772 & $14,872,135$ & 5.2 & 379 & $7,319,246$ & 5.2 & 393 & $7,552,889$ & 5.2 & $2(1-5)$ \\
\hline $40-49$ & 885 & $14,732,844$ & 6.0 & 440 & $7,263,028$ & 6.1 & 445 & $7,469,816$ & 6.0 & $3(1-6)$ \\
\hline 50-59 & 1650 & $13,516,050$ & 12.2 & 899 & $6,726,066$ & 13.4 & 751 & $6,789,984$ & 11.1 & $3(1-7)$ \\
\hline 60-69 & 2357 & $10,420,187$ & 22.6 & 1246 & $5,344,994$ & 23.3 & 1111 & $5,075,193$ & 21.9 & $3(1-7)$ \\
\hline 70-79 & 3094 & $6,931,652$ & 44.6 & 1798 & $3,866,840$ & 46.5 & 1296 & $3,064,812$ & 42.3 & $4(1-9)$ \\
\hline 80-89 & 2859 & $3,495,850$ & 81.8 & 1914 & 2,252,297 & 85.0 & 945 & $1,243,553$ & 76.0 & $6(1-11)$ \\
\hline$\geq 90$ & 563 & 617,841 & 91.1 & 415 & 467,360 & 88.8 & 148 & 150,481 & 98.4 & $5(2-10)$ \\
\hline Total & 13,663 & $102,324,750$ & 13.4 & 7823 & $51,713,460$ & 15.1 & 5840 & $50,611,290$ & 11.5 & $4(1-8)$ \\
\hline $\begin{array}{l}\text { Age- } \\
\text { standardized }^{\mathrm{c}}\end{array}$ & & & $13.1(12.9-13.3)$ & & & $13.6(13.3-13.9)$ & & & $12.5(12.2-12.9)$ & \\
\hline
\end{tabular}

Abbreviations: $H Z$ herpes zoster

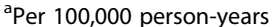

${ }^{\mathrm{b}}$ For inpatient primary diagnoses only

'Directly standardized to the age distribution in the 2000 Danish Census using the following weights: 0.13 for $0-9$ years, 0.11 for $10-19$ years, 0.14 for 20-29 years, 0.15 for $30-39$ years, 0.14 for $40-49$ years, 0.14 for $50-59$ years, 0.09 for $60-69$ years, 0.07 for $70-79$ years, 0.03 for $80-89$ years, and 0.01 for $\geq 90$ years

\section{Comorbidity}

A large proportion of persons with HZ had comorbidity. As measured by the CCI, $44 \%$ had no comorbidity, $17 \%$ had moderate comorbidity, $17 \%$ had severe comorbidity, and $21 \%$ had very severe comorbidity (Table $3)$. The most prevalent diagnoses were autoimmune diseases (17\%), chronic pulmonary disease (14\%), nonmetastatic solid tumor (13\%), cerebrovascular disease
(11\%), congestive heart failure (7.7\%), connective tissue disease (7.2\%), myocardial infarction (6.7\%), diabetes without end-organ damage (6.7 \%), ulcer disease (6.2\%), and lymphoma (6.1\%). In total, $21 \%$ had an active or previous cancer. Diseases possibly associated with immune dysregulation were recorded in $36 \%$ of $\mathrm{HZ}$ patients. The prevalence of HIV infection was $1.5 \%$. Median age and comorbidity burden were highest in

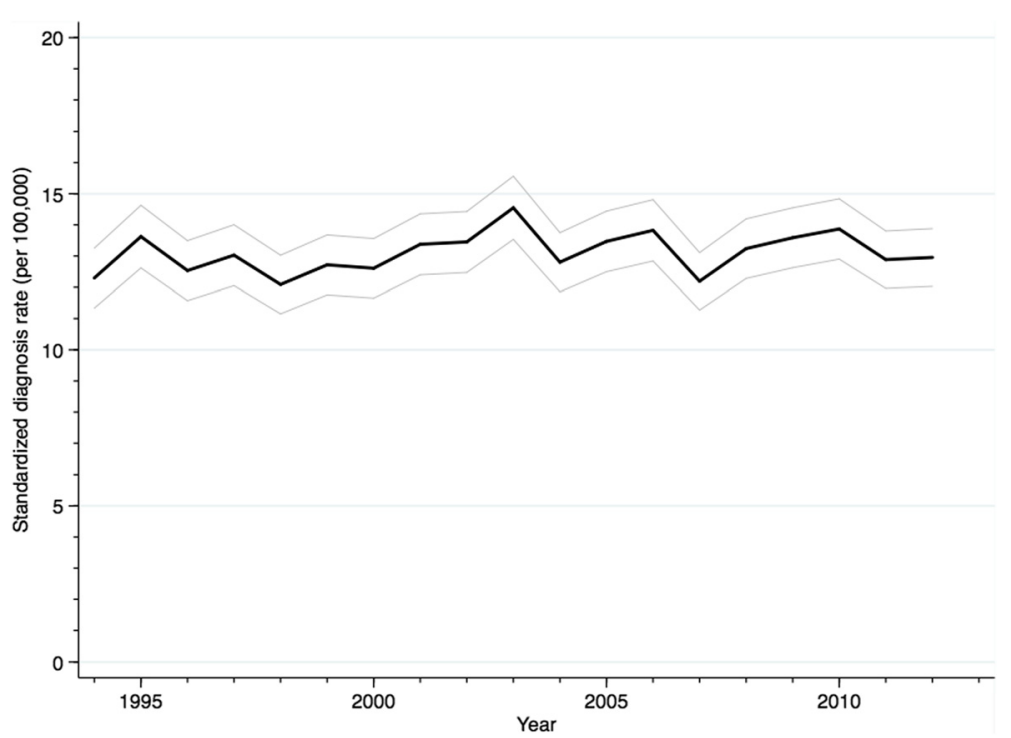

Fig. 1 Rates of first-time hospital-based diagnoses of herpes zoster, Denmark, 1994-2012, directly standardized to the age-distribution in the 2000 Danish Census 


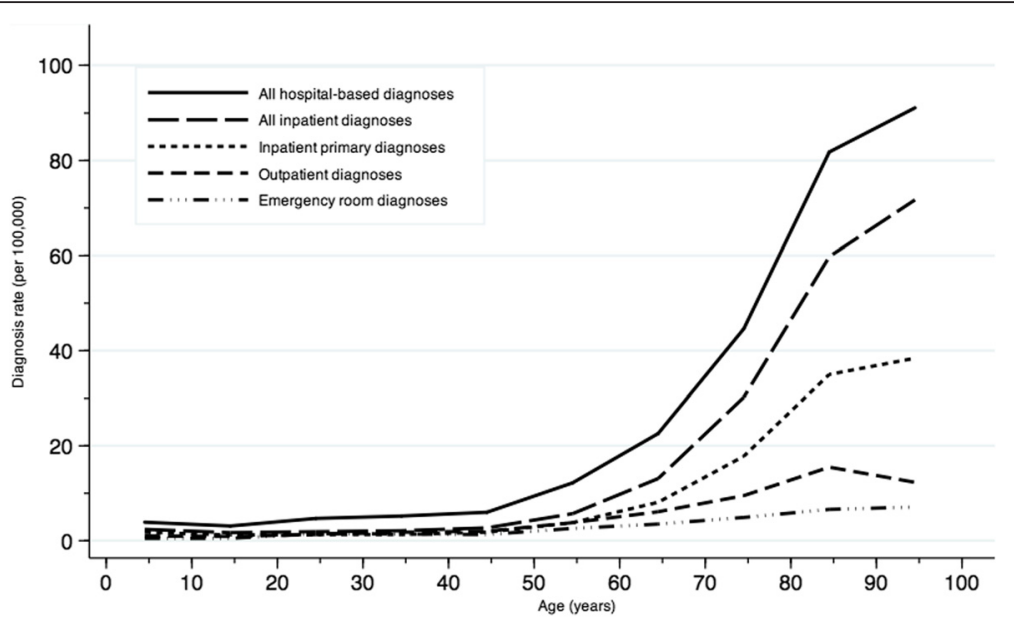

Fig. 2 Age-specific rates of hospital-based diagnoses of herpes zoster according to diagnosis types, Denmark, 1994-2012

Table 2 No. (\%) of types of first-time hospital-based diagnoses of HZ, Denmark, 1994-2012

\begin{tabular}{|c|c|c|c|c|c|c|c|c|}
\hline \multirow{3}{*}{ Type of hospital contact } & \multicolumn{6}{|c|}{ Calendar period } & \multirow{2}{*}{\multicolumn{2}{|c|}{ Total }} \\
\hline & \multicolumn{2}{|c|}{ 1994-1999 } & \multicolumn{2}{|c|}{$2000-2005$} & \multicolumn{2}{|c|}{ 2006-2012 } & & \\
\hline & & & & & & & & \\
\hline Emergency room & 765 & (19) & 655 & (15) & 610 & (12) & 2030 & (15) \\
\hline Outpatient clinic & 911 & (23) & 1035 & (24) & 1459 & (28) & 3405 & (25) \\
\hline Inpatient & 2323 & (58) & 2661 & (61) & 3244 & (61) & 8228 & (60) \\
\hline \multicolumn{9}{|l|}{ Type of diagnosis } \\
\hline Primary diagnosis & 3040 & (76) & 3036 & (70) & 3759 & (71) & 9835 & (72) \\
\hline Secondary diagnosis & 959 & (24) & 1315 & (30) & 1554 & (29) & 3828 & (28) \\
\hline \multicolumn{9}{|l|}{ Severity of HZ } \\
\hline Uncomplicated & 2873 & (72) & 3178 & (73) & 3580 & (67) & 9631 & (70) \\
\hline Complicated & 1126 & (28) & 1173 & (27) & 1733 & (33) & 4032 & (30) \\
\hline \multicolumn{9}{|l|}{ Extent of $\mathrm{HZ}$} \\
\hline Localized & 3390 & (85) & 3708 & (85) & 4235 & (80) & 11,333 & (83) \\
\hline Disseminated & 609 & (15) & 643 & (15) & 1078 & (20) & 2330 & (17) \\
\hline \multicolumn{9}{|l|}{ Diagnosis code (ICD-10 code) } \\
\hline HZ meningo-encephalitis (B02.0-1) & 62 & $(1.6)$ & 79 & $(1.8)$ & 196 & (3.7) & 337 & $(2.5)$ \\
\hline HZ encephalitis (B02.0) & 54 & (1.4) & 63 & $(1.4)$ & 146 & $(2.7)$ & 263 & (1.9) \\
\hline $\mathrm{HZ}$ meningitis (B02.1) & 8 & $(0.20)$ & 16 & $(0.37)$ & 50 & $(0.94)$ & 74 & $(0.54)$ \\
\hline $\mathrm{HZ}$ with other nervous system involvement (B02.2) & 323 & $(8.1)$ & 320 & (7.4) & 418 & (7.9) & 1061 & (7.8) \\
\hline HZ ophthalmicus (B02.3) & 517 & (13) & 530 & (12) & 655 & (12) & 1702 & (12) \\
\hline Disseminated HZ (B02.7) & 74 & (1.9) & 90 & (2.1) & 109 & (2.1) & 273 & (2.0) \\
\hline HZ with other complication (B02.8) & 150 & (3.8) & 154 & (3.5) & 355 & $(6.7)$ & 659 & $(4.8)$ \\
\hline HZ without complication (B02.9) & 2873 & (72) & 3178 & (73) & 3580 & (67) & 9631 & (71) \\
\hline Total & 3999 & (29) & 4351 & (32) & 5313 & (39) & 13,663 & $(100)$ \\
\hline
\end{tabular}

Abbreviations: HZ herpes zoster, ICD-10 International Classification of Diseases, 10th revision 
Table 3 Characteristics of 13,663 patients with a first-time hospital-based diagnosis of HZ, Denmark, 1994-2012

\begin{tabular}{|c|c|c|}
\hline Characteristic & No. & Percent \\
\hline \multicolumn{3}{|l|}{ Age group (years) ${ }^{a}$} \\
\hline $0-9$ & 492 & (3.6) \\
\hline $10-19$ & 368 & $(2.7)$ \\
\hline $20-29$ & 623 & $(4.6)$ \\
\hline $30-39$ & 772 & $(5.7)$ \\
\hline $40-49$ & 885 & $(6.5)$ \\
\hline $50-59$ & 1650 & (12) \\
\hline $60-69$ & 2357 & $(17)$ \\
\hline $70-79$ & 3094 & (23) \\
\hline $80-89$ & 2859 & $(21)$ \\
\hline$\geq 90$ & 563 & $(4.1)$ \\
\hline \multicolumn{3}{|l|}{ Sex } \\
\hline Women & 7823 & (57) \\
\hline Men & 5840 & (43) \\
\hline Any of the comorbidities identified & 8067 & (59) \\
\hline \multicolumn{3}{|l|}{ Charlson Comorbidity Index level } \\
\hline None & 6058 & (44) \\
\hline Moderate & 2364 & $(17)$ \\
\hline Severe & 2374 & $(17)$ \\
\hline Very severe & 2867 & (21) \\
\hline \multicolumn{3}{|l|}{ Comorbidities in the Charlson Comorbidity Index } \\
\hline Myocardial infarction & 921 & $(6.7)$ \\
\hline Congestive heart failure & 1050 & $(7.7)$ \\
\hline Peripheral vascular disease & 803 & $(5.9)$ \\
\hline Cerebrovascular disease & 1446 & (11) \\
\hline Dementia & 256 & $(1.9)$ \\
\hline Chronic pulmonary disease & 1911 & (14) \\
\hline Connective tissue disease & 983 & $(7.2)$ \\
\hline Ulcer disease & 848 & $(6.2)$ \\
\hline Mild liver disease & 171 & $(1.3)$ \\
\hline Diabetes without end-organ damage & 918 & $(6.7)$ \\
\hline Hemiplegia & 57 & $(0.42)$ \\
\hline Moderate to severe renal disease & 643 & $(4.7)$ \\
\hline Diabetes with end-organ damage & 419 & $(3.1)$ \\
\hline Non-metastatic solid tumor & 1755 & (13) \\
\hline Leukemia & 489 & (3.6) \\
\hline Lymphoma & 834 & $(6.1)$ \\
\hline Moderate to severe liver disease & 62 & $(0.45)$ \\
\hline Metastatic solid tumor & 331 & $(2.4)$ \\
\hline Acquired immune deficiency syndrome & 153 & $(1.1)$ \\
\hline Comorbidities associated with immune dysregulation & 4942 & (36) \\
\hline Stem cell or bone marrow transplant & 273 & $(2.0)$ \\
\hline Solid organ transplant & 152 & $(1.1)$ \\
\hline
\end{tabular}

Table 3 Characteristics of 13,663 patients with a first-time hospital-based diagnosis of HZ, Denmark, 1994-2012 (Continued)

\begin{tabular}{lll}
\hline Human immunodeficiency virus infection & 210 & $(1.5)$ \\
Primary immunodeficiency & 61 & $(0.45)$ \\
Any cancer & 2821 & $(21)$ \\
Any autoimmune disease & 2293 & $(17)$ \\
Hematologic & 73 & $(0.53)$ \\
Endocrine & 614 & $(4.5)$ \\
Central nervous system & 67 & $(0.49)$ \\
Gastrointestinal & 274 & $(2.0)$ \\
Skin & 315 & $(2.3)$ \\
Connective tissue disease & 1080 & $(7.9)$ \\
Pulmonary & 31 & $(0.23)$ \\
Ocular & 94 & $(0.69)$ \\
\hline
\end{tabular}

Abbreviations: $H Z$ herpes zoster

${ }^{a}$ Overall, the age range was 0 to 103 years. Median age was 68 years: 71 years in women and 65 years in men

patients with inpatient and secondary $\mathrm{HZ}$ diagnoses (Additional file 1: Table S3).

\section{Mortality}

The 30-day mortality for persons with $\mathrm{HZ}$ was $3 \%$, corresponding to $7 \%(434 / 6059)$ of all deaths in the cohort in total. We observed higher mortality in patients with HZ compared with the general population (Table 4). The overall SMR was 1.8 (95 \% CI: 1.7-1.8): 1.6 (95\% CI: $1.6-1.7)$ in women and 2.0 (95 \% CI: 1.9-2.1) in men. The highest SMRs were found in young patients. However, after stratifying by comorbidity level, the SMR was not increased in patients without comorbidity (SMR 1.0; $95 \%$ CI: 0.9-1.0). SMRs according to subtypes of HZ diagnoses are shown in Additional file 1: Table S4.

\section{Discussion}

In this nationwide Danish study, the rate of hospital-based HZ diagnoses was stable at around 13 per 100,000 person-years over a study period of 19-years. The rate was 3-6 per 100,000 person-years for persons aged below 50 years, increasing by approximately twofold with each consecutive decade of age. Thirty percent of patients had complicated HZ and comorbidity was prevalent, particularly diseases involving immune dysregulation.

The age-specific hospitalization rates from the present study and previous European studies are shown in Additional file 1: Figure S3. While the overall and agespecific inpatient hospital diagnosis rates in Denmark accord with previous studies [11-24], however there is considerable variation across countries. This variation may result from differences in hospital admission practices or health-seeking behavior, as the overall incidence 
Table 4 SMRs among patients with a first-time hospital-based diagnosis of HZ, Denmark, 1994-2012

\begin{tabular}{|c|c|c|c|}
\hline & Observed & Expected & $\operatorname{SMR}(95 \% \mathrm{Cl})^{\mathrm{a}}$ \\
\hline Overall & 6059 & 3414 & $1.8(1.7-1.8)$ \\
\hline \multicolumn{4}{|c|}{ Age group (years) } \\
\hline $0-9$ & 12 & 1.1 & $10.7(6.1-18.9)$ \\
\hline $10-19$ & 18 & 1.1 & $16.4(10.4-26.1)$ \\
\hline $20-29$ & 34 & 4.0 & $8.5(6.1-12.0)$ \\
\hline $30-39$ & 66 & 11 & $5.8(4.6-7.4)$ \\
\hline $40-49$ & 143 & 30 & $4.8(4.1-5.7)$ \\
\hline $50-59$ & 451 & 124 & $3.6(3.3-4.0)$ \\
\hline $60-69$ & 916 & 350 & $2.6(2.5-2.8)$ \\
\hline $70-79$ & 1874 & 988 & $1.9(1.8-2.0)$ \\
\hline $80-89$ & 2080 & 1507 & $1.4(1.3-1.4)$ \\
\hline$\geq 90$ & 465 & 397 & $1.2(1.1-1.3)$ \\
\hline \multicolumn{4}{|l|}{ Sex } \\
\hline Women & 3530 & 2166 & $1.6(1.6-1.7)$ \\
\hline Men & 2529 & 1248 & $2.0(1.9-2.1)$ \\
\hline \multicolumn{4}{|c|}{ Charlson Comorbidity Index level } \\
\hline None & 1663 & 1651 & $1.0(1.0-1.1)$ \\
\hline Moderate & 1229 & 784 & $1.6(1.5-1.7)$ \\
\hline Severe & 1346 & 506 & $2.7(2.5-2.8)$ \\
\hline Very severe & 1821 & 473 & $3.8(3.7-4.0)$ \\
\hline \multicolumn{4}{|c|}{$\begin{array}{l}\text { Comorbidity associated with } \\
\text { immune dysregulation }\end{array}$} \\
\hline No & 3378 & 2513 & $1.3(1.3-1.4)$ \\
\hline Yes & 2681 & 901 & $3.0(2.9-3.1)$ \\
\hline \multicolumn{4}{|c|}{$\begin{array}{l}\text { Any of the identified } \\
\text { comorbidities }\end{array}$} \\
\hline No & 1532 & 1555 & $1.0(0.9-1.0)$ \\
\hline Yes & 4527 & 1858 & $2.4(2.4-2.5)$ \\
\hline
\end{tabular}

Abbreviations: $\mathrm{Cl}$ confidence interval, $H Z$ herpes zoster, SMR Standardized mortality ratios

${ }^{a}$ Computed using indirect standardization with the Danish general population as reference. Due to rounding the estimates and upper and lower confidence bounds may appear the same

rate in the general population varies only slightly across Europe [2]. Nevertheless, the nearly exponential increase in the rate of hospital-based $\mathrm{HZ}$ diagnoses after age 50 years $[11-18,20-23]$ and the female predominance $[12,13,16,18,19,21]$ in our study are comparable with results from the previous studies. However, none of these studies presented data specifically on $\mathrm{HZ}$ diagnosed in hospital-based outpatient clinics, which accounted for one-fourth of patients in our study.

We observed a shorter length of hospital stay (mean 6.2 days) compared to previous studies (mean 7.5 to 11.2 days) [12, 13, 17-19, 22, 25, 26]. Our result was closest to that reported in a Swedish study [18], which also had a similar diagnosis rate and proportion of complicated infections. The shorter length of stay may be explained by hospitalization of milder cases of $\mathrm{HZ}$ in Denmark and Sweden, as the proportion of complicated infections (mainly ocular and neurological) was approximately twice as high in Southern Europe [12, 14, 19, 20, 25, 26]. Studies from Southern Europe also reported a higher prevalence of predisposing conditions, such as HIV [12, 14, 16, 20], organ transplantation [12, 16], diabetes [16], and 'blood dyscrasias and some immune deficiencies' [16] in HZ patients. Frequencies of malignancy $[14,16,20]$ and connective tissue disease [16] were comparable to the results in our study. Finally, the length of stay for patients with neurological complications in our data accords with Italian and French data [19, 25, 26], further suggesting that differences in admission practices play a role. The slight temporal increase in the diagnosis rate of $\mathrm{HZ}$ encephalitis and meningitis in our study may result from increased use of polymerase chain reaction technology for detecting varicella-zoster virus in cerebrospinal fluid [27].

Chronic pulmonary disease, connective tissue disease, cancer, HIV, and solid organ transplantation were relatively more frequent in our study compared with other selected Danish patient populations [28-31]. This finding is consistent with the increased risk of $\mathrm{HZ}$ in patients with immune dysregulation due to either disease pathophysiology or treatment (e.g., with glucocorticoids) [1]. Apart from posing an additional burden to these patients, HZ could complicate their treatment, for instance by delaying chemotherapy for cancer. We lacked data on HZ treated in general practice and had no comparison cohort, which prevented us from examining whether $\mathrm{HZ}$ was associated with increased mortality in patients with certain comorbidities. Although we found increased mortality among patients with comorbidity, we obtained this result using standardization to the entire general population, including those without comorbidity. Thus, the increased SMRs may potentially reflect excess mortality from the comorbid condition rather than from an interaction between $\mathrm{HZ}$ and the comorbid condition. The difference in SMRs by age could also be explained by use of the general population as reference. A high prevalence of the exposure (HZ) in the general population would bias the SMR towards the null [32]. Because the prevalence of $\mathrm{HZ}$ increases with age, the risk of this bias also may increase with age, potentially explaining our finding of lower SMRs in the oldest age groups.

We used a comprehensive nationwide database to study hospital-based HZ diagnoses within a universal healthcare system, which limits selective inclusion of specific hospitals, insurance groups, or age groups. Nonetheless, our study has some limitations. Since 2002, reimbursements to public and private hospitals have been administered using the Diagnosis Related Group (DRG) system in the DNPR [6], 
which may have affected physicians' choice of primary and secondary diagnosis codes. As well, the completeness and validity of $\mathrm{HZ}$ diagnoses in the DNPR is unknown. Still, other studies have found high diagnostic accuracy with positive predictive values ranging from 72 to $100 \%$ [33-37]. Although there is a specific code for specifying consultation with post-herpetic neuralgia (ICD-10 G53.0), it is possible that some codes, particularly 'other nervous system involvement,' were assigned alone to patients who had this chronic complication rather than acute HZ. However, we consider such misclassification of minor importance because these patients experienced recent varicella-zoster virus reactivation.

Our comorbidity assessment has some limitations. The positive predictive value for diagnoses included in the $\mathrm{CCI}$ are known to vary depending on the disease, department of origin, and reference standard [6]. Moreover, incompleteness is expected for conditions that are treated primarily in general practice, e.g., diabetes. Another concern is underestimation early in the study period due to left-censoring of outpatient and emergency room diagnoses before 1994. Similarly, changes in coding when new medical treatments are introduced may explain the lack of $\mathrm{HZ}$ patients with bone marrow transplantations early in the study period.

The majority of patients with HZ in Denmark are treated in general practices [38], which are not subject to systematic monitoring in national registries. Thus, analysis of temporal trends in our study may not reflect true changes in disease incidence in the population. Administrative factors (e.g., changing admission practices) are also important in determining whether patients receive a hospital-based diagnosis. As well, the lack of primary care data may have caused underestimation of the SMRs [32].

\section{Conclusions}

This nationwide Danish study provided pre-vaccination estimates of the epidemiology of hospital-based HZ. Because hospital-based treatment is likely linked to presence of complications or underlying diseases, our study likely comprises the most severe cases of $\mathrm{HZ}$. Indeed, $30 \%$ of patients had complicated $\mathrm{HZ}$ and diseases associated with increased risk of severe HZ (e.g., hematological cancer $[3,4])$ were prevalent. These results stress the importance of considering hospital-based diagnoses in studies assessing the overall burden of $\mathrm{HZ}$ in the population.

\section{Availability of data and materials}

No additional data are available. According to the Danish Act on Processing of Personal Data, private and public institutions may obtain the health data used in the current study, after obtaining the necessary projectspecific approvals.

\section{Additional file}

Additional file 1: Supplementary figures and tables. (PDF 886 kb)

\section{Abbreviations}

Cl: confidence interval; CPR: central personal register; DNPR: Danish National Patient Registry; ICD: International Classification of Diseases; HIV: human immunodeficiency virus; HZ: herpes zoster; SMR: standardized mortality ratio.

\section{Competing interests}

The authors declare that they have no competing interests.

\section{Authors' contributions}

SAJS conceived the study idea, carried out the analyses, reviewed the literature, and wrote the initial draft. JK performed initial data management. SAJS, JK, MV, HCS, and HTS participated in designing the study, critically revised the manuscript for intellectual content, and approved the final version.

\section{Acknowledgement}

This work was supported by 'Dagmar Marshalls Fond', 'Friedrich Wilhelm Frank og Hustru Angelina Franks Mindelegat', 'Kgl. Hofbuntmager Aage Bangs Fond', Aarhus University, and the Program for Clinical Research Infrastructure established by the Lundbeck and the Novo Nordisk Foundations. None of the funding sources had a role in the design, conduct, analysis, or reporting of the study. The Department of Clinical Epidemiology, however, is involved in studies with funding from various companies as research grants to (and administered by) Aarhus University. None of these studies have any relation to the present study.

\section{Author details}

${ }^{1}$ Department of Clinical Epidemiology, Aarhus University Hospital, Olof Palmes Allé 43-45, DK-8200 Aarhus N, Denmark. ${ }^{2}$ Research Unit and Section for General Practice, Department of Public Health, Aarhus University, Aarhus, Denmark. ${ }^{3}$ Department of Clinical Microbiology, Aalborg University Hospital, Aalborg, Denmark. ${ }^{4}$ Department of Clinical Medicine, Aalborg University, Aalborg, Denmark.

Received: 14 September 2015 Accepted: 22 January 2016 Published online: 01 March 2016

\section{References}

1. Wilson JF. Herpes zoster. Ann Intern Med. 2011;154(5):ITC31-15.

2. Pinchinat $\mathrm{S}$, Cebrián-Cuenca AM, Bricout H, Johnson RW. Similar herpes zoster incidence across Europe: results from a systematic literature review. BMC Infect Dis. 2013;13:170.

3. Habel LA, Ray GT, Silverberg MJ, Horberg MA, Yawn BP, Castillo AL, et al. The epidemiology of herpes zoster in patients with newly diagnosed cancer. Cancer Epidemiol Biomarkers Prev. 2013;22(1):82-90.

4. Tran TN, Ray GT, Horberg MA, Yawn BP, Castillo AL, Saddier P, et al. Complications of herpes zoster in cancer patients. Scand J Infect Dis. 2014; 46(7):528-32.

5. Schmidt M, Pedersen L, Sørensen HT. The Danish Civil Registration System as a tool in epidemiology. Eur J Epidemiol. 2014;29(8):541-9.

6. Schmidt M, Schmidt SAJ, Sandegaard JL, Ehrenstein V, Pedersen L, Sørensen HT. The Danish National Patient Registry: a review of content, data quality, and research potential. Clin Epidemiol. 2015;7:449-90.

7. Ording AG, Garne JP, Nyström PMW, Cronin-Fenton D, Tarp M, Sørensen HT, et al. Hospital recorded morbidity and breast cancer incidence: a nationwide population-based case-control study. PLoS One. 2012;7(10): e47329.

8. Rasmussen JG. Vaccine reaches Denmark with an 8-year delay. Dagens medicin [Internet]. [cited 2015 Feb 18]. Available from: Available from: http://www.dagensmedicin.dk/nyheder/vaccine-nar-til-danmark-med-ottear-forsinkelse/.

9. Charlson ME, Pompei P, Ales KL, MacKenzie CR. A new method of classifying prognostic comorbidity in longitudinal studies: development and validation. J Chronic Dis. 1987;40(5):373-83.

10. Curtin LR, Klein RJ. Direct standardization (age-adjusted death rates). Healthy People 2000 Stat Notes. 1995;6:1-10. 
11. Bilcke J, Ogunjimi B, Marais C, de Smet F, Callens M, Callaert K, et al. The health and economic burden of chickenpox and herpes zoster in Belgium. Epidemiol Infect. 2012;140(11):2096-109.

12. Mesquita M, Froes F. Hospital admissions for herpes zoster in Portugal between 2000 and 2010. Acta Med Port. 2013;26(5):531-6.

13. de Melker $H$, Berbers $G$, Hahné $S$, Rümke $H$, van den Hof $S$, de Wit $A$, et al. The epidemiology of varicella and herpes zoster in The Netherlands: implications for varicella zoster virus vaccination. Vaccine. 2006;24(18): 3946-52.

14. Gil A, Gil R, Alvaro A, San Martín M, González A. Burden of herpes zoster requiring hospitalization in Spain during a seven-year period (1998-2004). BMC Infect Dis. 2009;9:55.

15. Gil-Prieto R, Walter S, Gonzalez-Escalada A, Garcia-Garcia L, Marín-García P, Gil-de-Miguel A. Different vaccination strategies in Spain and its impact on severe varicella and zoster. Vaccine. 2014;32(2):277-83.

16. Gonzalez Chiappe S, Sarazin M, Turbelin C, Lasserre A, Pelat C, Bonmarin I, et al. Herpes zoster: Burden of disease in France. Vaccine. 2010;28(50): 7933-8.

17. Brisson M, Edmunds WJ. Epidemiology of Varicella-Zoster virus in England and Wales. J Med Virol. 2003;70 Suppl 1:S9-14.

18. Studahl M, Petzold M, Cassel T. Disease burden of herpes zoster in Swedenpredominance in the elderly and in women - a register based study. BMC Infect Dis. 2013;13:586.

19. Gabutti G, Serenelli C, Cavallaro A, Ragni P. Herpes zoster associated hospital admissions in Italy: review of the hospital discharge forms. Int J Environ Res Public Health. 2009;6(9):2344-53.

20. Di Legami V, Gianino MM, Ciofi degli Atti M, Massari M, Migliardi A, Tomba GS, et al. Epidemiology and costs of herpes zoster: background data to estimate the impact of vaccination. Vaccine. 2007;25(43):7598-604.

21. Ultsch B, Siedler A, Rieck T, Reinhold T, Krause G, Wichmann O. Herpes zoster in Germany: quantifying the burden of disease. BMC Infect Dis. 2011; 11:173.

22. Gialloreti LE, Merito M, Pezzotti P, Naldi L, Gatti A, Beillat M, et al. Epidemiology and economic burden of herpes zoster and post-herpetic neuralgia in Italy: a retrospective, population-based study. BMC Infect Dis. 2010;10:230

23. Fairley CK, Miller E. Varicella-zoster virus epidemiology-a changing scene? J Infect Dis. 1996;174 Suppl 3:S314-9.

24. Siedler A, Dettmann M. Hospitalization with varicella and shingles before and after introduction of childhood varicella vaccination in Germany. Hum Vaccin Immunother. 2014;10(12):3594-600.

25. Blein C, Gavazzi G, Paccalin M, Baptiste C, Berrut G, Vainchtock A. Burden of herpes zoster: the direct and comorbidity costs of herpes zoster events in hospitalized patients over 50 years in France. BMC Infect Dis. 2015;15(1):350.

26. Levi M, Bellini I, Capecchi L, Pieri L, Bechini A, Boccalini S, et al. The burden of disease of Herpes Zoster in Tuscany. Hum Vaccin Immunother. 2015; 11(1):185-91.

27. Linde A, Klapper PE, Monteyne P, Echevarria JM, Cinque P, Rozenberg F, et al. Specific diagnostic methods for herpesvirus infections of the central nervous system: a consensus review by the European Union Concerted Action on Virus Meningitis and Encephalitis. Clin Diagn Virol. 1997;8(2): 83-104.

28. Schmidt M, Jacobsen JB, Lash TL, Bøtker HE, Sørensen HT. 25 year trends in first time hospitalisation for acute myocardial infarction, subsequent short and long term mortality, and the prognostic impact of sex and comorbidity: a Danish nationwide cohort study. BMJ. 2012;344:e356.

29. Schmidt M, Jacobsen JB, Johnsen SP, Bøtker HE, Sorensen HT. Eighteen-year trends in stroke mortality and the prognostic influence of comorbidity. Neurology. 2014;82(4):340-50.

30. Lash TL, Johansen MB, Christensen S, Baron JA, Rothman KJ, Hansen JG, et al. Hospitalization rates and survival associated with COPD: A Nationwide Danish Cohort Study. Lung. 2010;189(1):27-35.

31. Jensen $A \varnothing$, Lamberg $A L$, Jacobsen JB, Olesen $A B$, Sørensen HT. Nonmelanoma skin cancer and ten-year all-cause mortality: a population-based cohort study. Acta Derm Venereol. 2010;90(4):362-7.

32. Jones ME, Swerdlow AJ. Bias in the standardized mortality ratio when using general population rates to estimate expected number of deaths. Am J Epidemiol. 1998;148(10):1012-7.

33. Oxman MN, Levin M, Johnson GR, Schmader KE, Straus SE, Gelb LD, et al. A vaccine to prevent herpes zoster and postherpetic neuralgia in older adults. N Engl J Med. 2005;352(22):2271-84.
34. Rübben A, Baron JM, Grussendorf-Conen El. Routine detection of herpes simplex virus and varicella zoster virus by polymerase chain reaction reveals that initial herpes zoster is frequently misdiagnosed as herpes simplex. Br J Dermatol. 1997;137(2):259-61.

35. Scott FT, Johnson RW, Leedham-Green M, Davies E, Edmunds WJ, Breuer J. The burden of Herpes Zoster: a prospective population based study. Vaccine. 2006;24(9):1308-14.

36. Weinmann S, Chun C, Schmid DS, Roberts M, Vandermeer M, Riedlinger $K$, et al. Incidence and clinical characteristics of herpes zoster among children in the varicella vaccine era, 2005-2009. J Infect Dis. 2013;208(11):1859-68.

37. Rimland D, Moanna A. Increasing incidence of herpes zoster among Veterans. Clin Infect Dis. 2010;50(7):1000-5.

38. Østergaard K, Damgaard M, Kristiansen TB, Madsen KG. Herpes zoster incidence in persons above 50 years of age (article in Danish). Ugeskr Laeger. 2009;171(26):2194-7.

\section{Submit your next manuscript to BioMed Central and we will help you at every step:}

- We accept pre-submission inquiries

- Our selector tool helps you to find the most relevant journal

- We provide round the clock customer support

- Convenient online submission

- Thorough peer review

- Inclusion in PubMed and all major indexing services

- Maximum visibility for your research

Submit your manuscript at www.biomedcentral.com/submit

) Biomed Central 